\title{
K6. Studies on the Hypothermia in Neurosurgery with Special Reference to its Application.
}

\author{
M. Urabe, S. Yamamoto, T. Tsubokawa, M. Miyanaga, \\ M. Kikuchi, S. Kadoya, Y. Seki and Y. Ota \\ Dept. of Surg, School of Med., Univ. of Kanazawa
}

For the effective use of hypothermia in neurosurgery, it is necessary to know its optimal and critical temperature. In the case of surface cooling which most often used in neurosurgery, we investigated the responses of the body to the temperature to know the critical temperature.

(1) It was known from the examination of the cerebral arterio-venous oxygen difference, cerebral blood flow and direct measurement of oxygen demand that the oxygen debt of the brain tissue was caused at the temperature below $28-27^{\circ} \mathrm{C}$. This fact was also ascertained by the decrease in the cerebral arteriovenous difference of the glucose and the increase in the lacetic acid at the temperature below $28-27^{\circ} \mathrm{C}$. (2) The prevention of cerebral swelling by hypothermia was gained in the highest at the temperature $27^{\circ} \mathrm{C}$. There is the fact which venous pressure and pulmonary arterial pressure increase at $25-24^{\circ} \mathrm{C}$. (3) The irritability by operation disappeared at $29-28^{\circ} \mathrm{C}$ in cerebral cortex, at $28-27^{\circ} \mathrm{C}$ in hypothalamus, at $26-25^{\circ} \mathrm{C}$ in the thalamus concerning the respiration and blood pressure.

The critical temperature of surface cooling in neurosurgery is at $27-26^{\circ} \mathrm{C}$, because the disadvantageous reactions, like oxygen debt of the brain tissue and increased venous pressure and pulmonary arterial pressure, of hypothermia appeared at this temperature. The optimal temperature to be applied in neurosurgery should be determined so adequately that responses caused by hypothermia were in the safe of the life in consideration of the above mentioned changes.

In order to occlude completely the cerebral blood flow, the profound hypothermia should be applied. In this occasion, the surface cooling was not reliable, because when below $27^{\circ} \mathrm{C}$, it caused the oxygen debt and acidosis, resulting in rewarming shock. We use the core cooling by means of extracorporeal circulation, so as to make rapid cooling and to keep the cerebral blood flow in constant level. 